\title{
Diabetes can change the viscoelastic properties of lymphocytes
}

\author{
N. Parvanehpour ${ }^{1} \cdot$ Shahrokh Shojaei ${ }^{2,3} \cdot$ S. Khorramymehr ${ }^{5} \cdot$ V. Goodarzi $^{6} \cdot$ F. Hejazi $^{2,4} \cdot$ V. Faghihi Rezaei $^{2}$
}

Received: 18 May 2018 / Accepted: 25 August 2018 / Published online: 1 September 2018

(c) The Author(s) 2018

\begin{abstract}
Mechanical properties of the cells are among the most highlighted area of interests among researchers for decades. Not only many of the cells' crucial functional characteristics such as adherence to the cellular substrate, migration abilities and morphological factors are directly influenced by their mechanical properties but also changes in these traits could have importance in diagnosis and even treatments of some serious diseases. The general mechanical properties of the cells are associated with some intercellular characteristics such as arrangement and organization of the actin fibers and cytoskeleton architecture. Any changes due to pathological conditions in the molecular and cellular processes related to these elements can alter the cells' mechanical characteristics. In this paper, the viscoelastic properties of diabetic and normal lymphocytes were analyzed and compared by application of the iron nanoparticles attached to the cellular membrane and putting the cells in a magnetic field with certain frequency and intensity. Step force was applied to the normal and diabetic lymphocytes and their membrane displacement was tracked by special software and plotted with respect to time. Fitting the experimental data on theoretical formulation of standard linear viscoelastic model, it was demonstrated that diabetic lymphocytes have significantly different viscoelastic characteristics. The results of this paper can be of importance in assessments of diabetic lymphocytes' abilities to fulfill their immune surveillance tasks.
\end{abstract}

Keywords Mechanical properties $\cdot$ Viscoelastic $\cdot$ Lymphocytes $\cdot$ Diabetes

\section{Introduction}

Cell mechanical properties play pivotal roles in vital characteristics of cells. Many of the biophysical and biological peculiarities are determined by viscoelastic properties of

Shahrokh Shojaei

shahrokh.shojaei@gmail.com

1 Department of Biomedical Engineering, South Tehran Branch, Islamic Azad University, Tehran, Iran

2 Department of Biomedical Engineering, Central Tehran Branch, Islamic Azad University, Tehran 13185/768, Iran

3 Stem cells Research Center, Tissue Engineering and Regenerative Medicine Institute, Central Tehran Branch, Islamic Azad University, Tehran 13185/768, Iran

4 Hard Tissue Engineering Research Center, Tissue Engineering and Regenerative Medicine Institute, Central Tehran Branch, Islamic Azad University, Tehran 13185/768, Iran

5 Department of Biomedical Engineering, Sciences and Research Branch, Islamic Azad University, Tehran, Iran

6 Applied Biotechnology Research Center, Baqiyatallah University of Medical Sciences, Tehran 19945/546, Iran cells (Hayot et al. 2012; Hecht et al. 2015). For instance, it has been illustrated that interaction of a cell and the extracellular matrix is regulated by the cell's mechanical properties (Trappmann and Chen 2013) or these mechanical traits have significant role in cell signaling (Humphrey et al. 2014). In addition, the cells' mechanical properties can be regarded as markers of differentiation (González-Cruz et al. 2012; Mathieu and Loboa 2012), pathology (Lekka et al. 2012; Rebelo et al. 2013; Suresh et al. 2015) and transformation (Plodinec et al. 2012). Since different cell sources and different methods such as micropipette aspiration (Zhao et al. 2009), atomic force microscopy (AFM) (Cartagena and Raman 2014; Hecht et al. 2015), magnetic beads microrheometry (Bausch et al. 1998) and others have been utilized for determination of cells' viscoelastic properties, there is a relative incongruity in results. Therefore, the mechanical properties of cells can be regarded as biomarkers that can be used in diagnosis of some diseases and analyzing the appropriate functioning of cells. In contrast to other methods of measuring viscoelastic properties, the use of magnetic field encompasses the advantage of not having direct contact with the cell body. In the methods such as AFM which include 
direct contact of an external tip or probe with the same dimension of a cell would lead to active cellular reaction that can easily change the mechanical properties (Guck et al. 2005). In addition, special preparations that are included in some other methods can alter the physiological and biological conditions and lead to results which are significantly different from ordinary homeostatic conditions. Using nanomagnetic adhesive beads accompanied with low-level field seems to have the lowest intervention and, therefore, gives rise to one of the most precise answers. Furthermore, magnetic-oriented approaches seem to be cheaper and simpler in comparison to other methods and so it can be widely and easily used in diagnostic and therapeutic purposes.

Lymphocytes are a small form of leukocytes that can make significant contribution in immune responses. The metabolism and natural biological processes within these cells change due to some diseases such as diabetes (Otton and Curi 2002; Otton and Curi 2002) and, therefore, it is expected to see alteration in membrane mechanical properties in normal and diabetic lymphocytes. In this research, the viscoelastic properties of normal and diabetic lymphocytes were determined and compared by low magnetic field.

\section{Materials and methods}

\section{Cell culture}

The lymphocytes in normal and diabetic groups were provided by Iranian Biological Research Center by ficoll method. RPMI 1640 media contained 10\% FBS, 1\% penicillin/streptomycin and $1 \mu \mathrm{g} / \mathrm{mL}$ phytohemagglutinin (PHA). The cell suspensions of two groups were incubated separately in culture medium for $18 \mathrm{~h}$, followed by addition of magnetic $\mathrm{Fe}_{3} \mathrm{O}_{4}$ nanoparticles and glucose with certain concentration. The cells of both groups were incubated for another $24 \mathrm{~h}$ in $\mathrm{CO}_{2}$ incubator for absorption of the magnetic nanoparticles.

\section{Magnetic field application}

Since the lymphocytes are characterized as non-adhesive cell types, for test one droplet of the cell suspension was applied to the laboratory neubauer lam. Cells were transferred on neubauer lam and their displacements were recorded after application of the magnetic field under the optical microscope $(1600 \times)$. For each test, first a single cell has been located and different magnitudes of forces were applied under the effect of different magnetic fields. The displacement of cells under the effect of forces was recorded by a 2 mega pixels 60 frames per second camera. Figure 1 shows the schematic view of the inductance system. A teslameter device (Pazhoohesh Nasir Model 1394) was used for assessing the intensity of the magnetic system. This teslameter can sense the intensity of the magnetic field in three Cartesian coordinates with the accuracy of 0.001 . The cells were subjected to $840 \mu \mathrm{T}$ magnetic field of 0.2 sq.Hz.

\section{Magnetic inductance system}

With the use of a function generator, the desired wave form could be produced and after amplification to $4 \mathrm{~A}$ the electrical current was applied to a coil. Magnetic field has the effects on magnetic nanoparticles which are connected to cell membrane. The coil has two cores. The central iron core has the radius of $2.5 \mathrm{~cm}$ and the length of $7 \mathrm{~cm}$ and the $\mathrm{sec}$ ondary Si core has the length of $2.5 \mathrm{~cm}$ and wrapped around the central core. The copper wire of $1.1 \mathrm{~mm}$ was twisted 400
Fig. 1 The schematic view of the system and its elements' arrangement

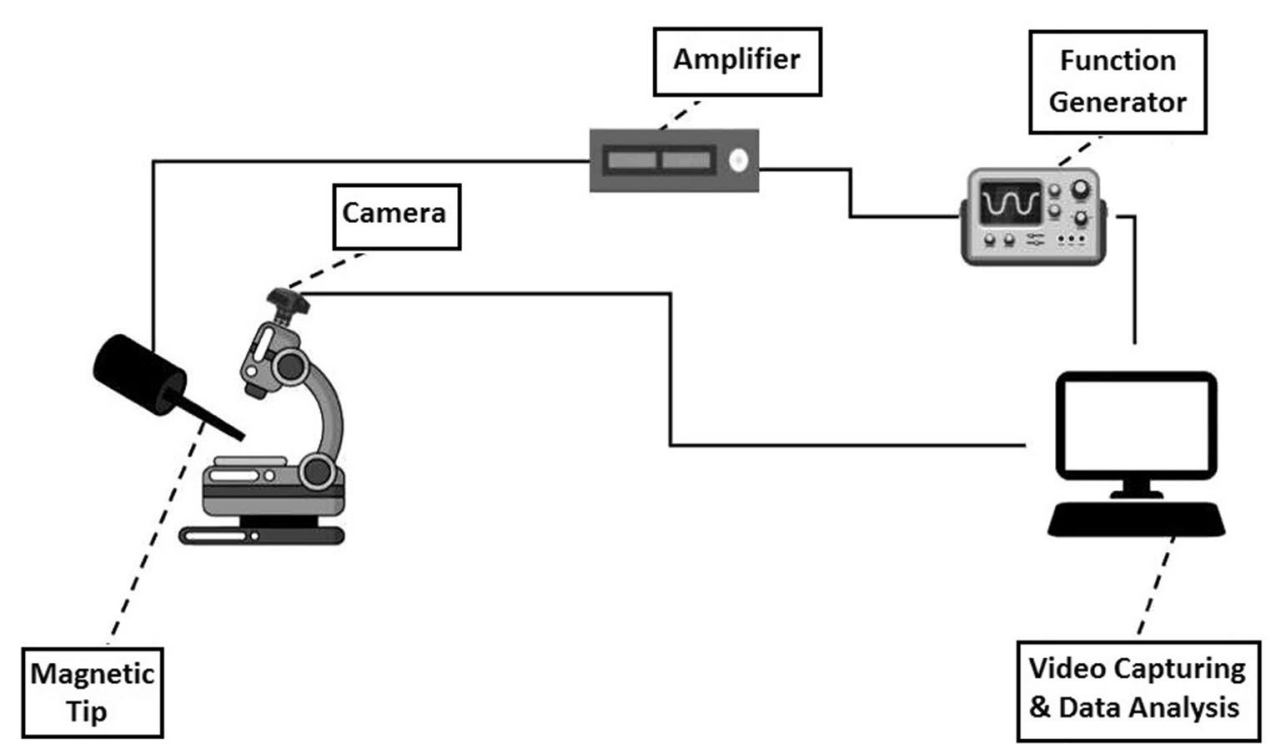


times around the cores. A teslameter with the accuracy of 0.001 was located in an appropriate location for determination of the magnitude of magnetic field.

\section{Date processing}

The videos are transferred into computer for processing. On the computer, four specific softwares for this purpose have been installed. The function generator software induces the desired wave form to the generator, Teslameter software that shows the magnitude of the magnetic field in micro Tesla in three Cartesian directions, video recording software that is related to the microscope and finally the software of Tracker (version 4.81) analyzing the displacement.

\section{Viscoelastic model}

Standard linear model was considered for force and displacement relation. This model consists of a spring and a Kelvin model in series. This model is shown in Fig. 2a.

The relation between stress and strain can be readily obtained as below (Eq. 1). This model has been widely used in previous biological researches (Lim et al. 2006).

$\sigma(t)+\frac{\frac{\eta}{E_{1}}}{1+\frac{E_{2}}{E_{1}}} \dot{\sigma}(t)=\frac{E_{2}}{1+\frac{E_{2}}{E_{1}}} \varepsilon(t)+\frac{\eta}{1+\frac{E_{2}}{E_{1}}} \dot{\varepsilon}(t)$

By substituting the coefficients with $p_{1}, q_{0}$ and $q_{1}$ we have Eq. 2.

$\sigma(t)+p_{1} \dot{\sigma}(t)=q_{0} \varepsilon(t)+q_{1} \dot{\varepsilon}(t)$

A
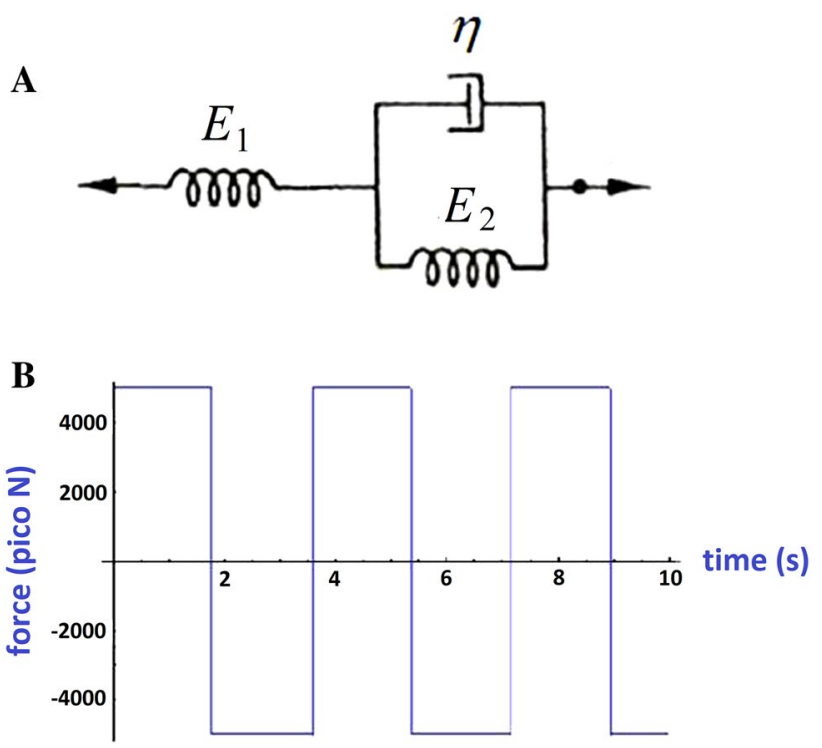

Fig. 2 a The standard linear model for viscoelastic materials. This model consists of two springs and a dashpot. b The applied square shape force with time. The samples were exposed for $15 \mathrm{~s}$
And by applying the step function with amplitude of $\sigma_{0}$ for the $\sigma$ function we will have Eq. 3 .

$\sigma(t)=\sigma_{0} H(t)$

$\rightarrow \varepsilon(t)=\frac{\sigma_{0}}{q_{1}}\left[\frac{1}{\lambda}\left(1-e^{-\lambda t}\right)+p_{1} e^{-\lambda t}\right] ; \lambda=\frac{q_{0}}{q_{1}}$

The parameters $p_{1}, q_{0}$ and $q_{1}$ should be determined in practical experiment. Figure $2 \mathrm{~b}$ shows the applied force. The frequency was $0.2 \mathrm{~Hz}, 4 \mathrm{~A}$ electrical current and the magnetic field $840 \mu \mathrm{T}$. The samples were exposed to this field for $15 \mathrm{~s}$.

\section{Statistical analysis}

All the tests were performed three times and in each test at least ten cells from each group were selected. $T$ test-paired statistical analysis was done for the three constants of the Eq. 3 and $P$ value below 0.05 was set as the criterion of significant difference.

\section{Results}

The displacement of the cell membrane in different normal and diabetic groups was analyzed after application of magnetic field. Figure 3 shows the medium of the Tracker software which includes the one specific cell. The $x$ - and $y$-direction displacements with time for the membrane have been depicted in Fig. 3.

Figure 4 shows the experimental and theoretical displacement variations with respect to time. Experimental points have been plotted and connected together and the theoretical curve was fitted by MATLAB software version (version 7.3) to the experimental data by obtaining the most appropriate constant values of Eq. 3. Figure 4a depicts the experimental and theoretical displacement curves with respect to time for normal lymphocyte and Fig. $4 \mathrm{~b}$ is related to the diabetic lymphocyte.

Table 1 shows the constant values of Eq. 3 for normal and diabetic lymphocytes based on the fitted curve to the experimental data.

\section{Discussion}

The mechanical properties of cells and tissues have attracted many scientists' and researchers' attention. It has been demonstrated that changes in mechanical characteristics of cell can be one of the best criteria in early diagnosis of many diseases. In addition, cellular wellfunctioning is attributed directly to mechanical properties 


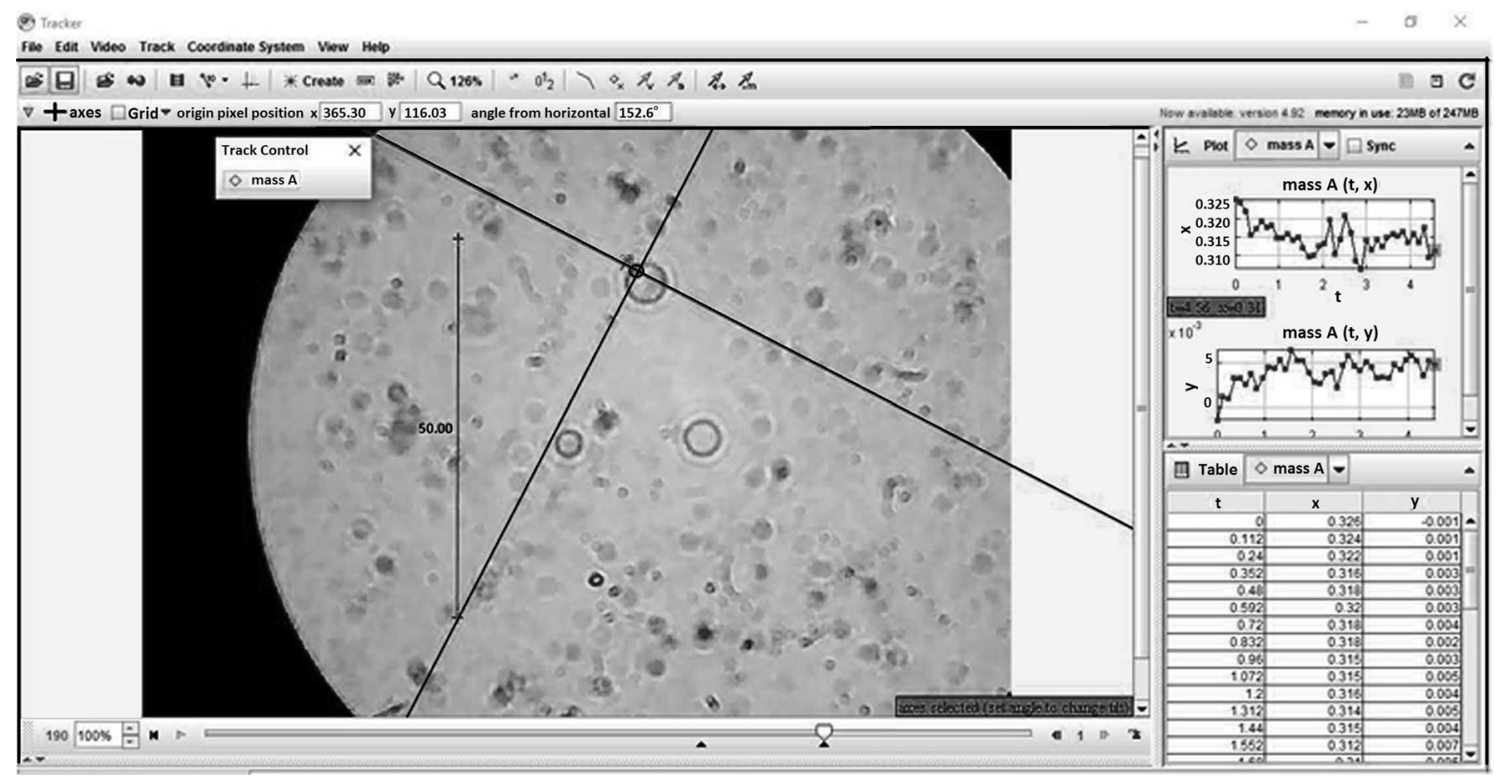

Fig. 3 The displacement of the cell membrane in $x$ and $y$ directions. Ten random cells were selected and the final result is the average of displacement in each group

of those cells. Due to these facts, recently some papers have been published on measuring viscoelastic properties of lymphocytes. To the best of our knowledge, this is the first time that the viscoelastic properties of normal and diabetic lymphocytes were measured and analyzed by this approach. While many researchers use micropipette aspiration or AFM method, in this research the viscoelastic properties of normal and diabetic lymphocytes have been investigated by application of magnetic field on iron nanoparticles-loaded cells. In this research, the viscoelastic properties of normal and diabetic lymphocytes were assessed and obtained. Magnetic iron nanoparticles have been added to the culture medium of the lymphocytes with certain concentration and by application of magnetic field in the graph of membrane displacement with respect to the time was plotted. By utilization of standard linear viscoelastic model, the mechanical properties of normal and diabetic lymphocytes were investigated and compared.

The results demonstrated that diabetes can change the mechanical properties of lymphocytes. Any physical (Rebelo et al. 2013; Rianna and Radmacher 2016) and chemical (Peetla et al. 2013) alterations at the cells' surface can readily lead to intervention in cells' vital functions, malfunction of entering and exit process of the necessary chemicals and even disorder in secretion of enzymes, proteins and other substances. As the previous researches have illustrated that diabetes can change some pivotal traits of lymphocytes such as metabolism rate (Otton and Curi 2002) or apoptosis (Otton et al. 2004), and also because of the interconnected physical and functional characteristics of the cells it was expected to see different mechanical properties for normal and diabetic lymphocytes. Our results have proven this hypothesis.

There are evidences that demonstrate the close relationship between the mechanical properties of cells' membrane and the organization and arrangement of their actin cytoskeleton (Lekka et al. 2011, 2012). It means that any change in actin fibers' arrangement and organization will cause change in mechanical properties of the whole cell. In addition, there are sufficient clues which illustrate the direct connection between the actin cytoskeleton remodeling properties and the cell motility. Past research works have shown that the remodeling of the dynamic filament meshwork is one of the primary influential factors in the cells' migration abilities (Gardel et al. 2010; Ridley et al. 2003). Therefore, the mechanical characteristics of cells including viscoelastic properties can be regarded as one of the essential parameters which depict the migration capability. This issue even becomes more highlighted for lymphocytes as their immune surveillance tasks are closely interconnected with their motile abilities (Dupré et al. 2015).

The results of this paper show a significant difference between the viscoelastic properties of normal and diabetic lymphocytes. Based on the previous discussion, this means a discrepancy exists between some vitally important characteristics of normal and diabetic lymphocytes such as their migration ability and, therefore, it can jeopardize diabetic lymphocytes' efficiency in immune responses.

By the hypothesis of regarding the architecture of the cytoskeleton as one the primary influential factors in 
Fig. 4 Membrane displacement with respect to the time after application of magnetic field for normal (a) and diabetic (b) lymphocytes. In both graphs the experimental data have been depicted together with theoretical data derived by the standard viscoelastic model
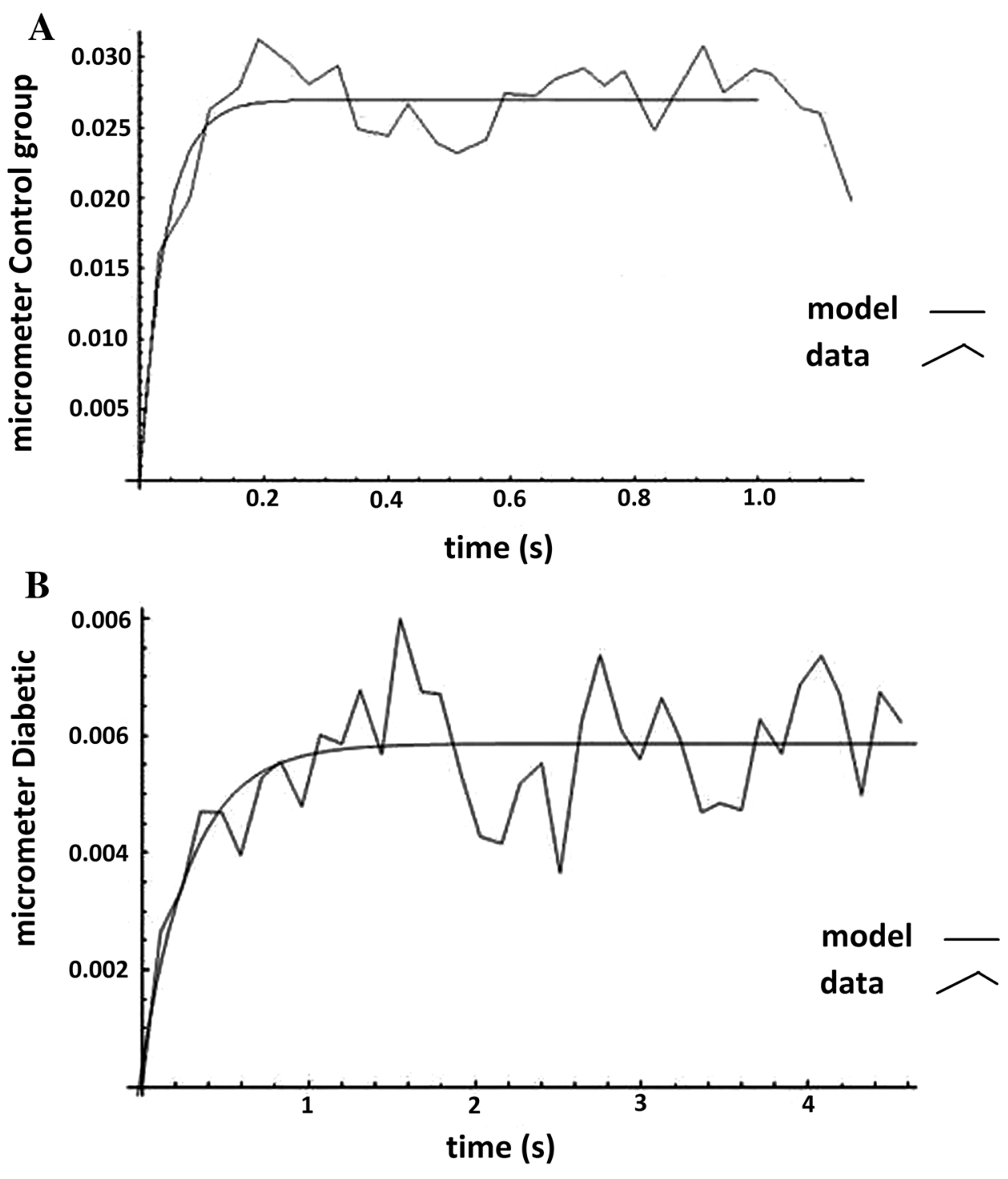

Table 1 The constants of the standard linear model of viscoelastic material for normal and diabetic lymphocytes

\begin{tabular}{llll}
\hline $\begin{array}{l}\text { Constants } \\
\text { of Eq. } 3\end{array}$ & Normal lymphocytes & Diabetic lymphocytes & $P$ value \\
\hline$p_{1}$ & $0.0074 \pm 0.0008$ & $0.2522 \pm 0.0036$ & $\leq 0.05$ \\
$q_{0}$ & $0.1852 \pm 0.03145$ & $0.8528 \pm 0.0752$ & $\leq 0.05$ \\
$q_{1}$ & $0.0003 \pm 4.1 \times 10^{-5}$ & $0.0175 \pm 0.00277$ & $\leq 0.05$ \\
\hline
\end{tabular}

total mechanical properties of a cell, we can associate the changes in viscoelastic properties of diabetic lymphocytes to the molecular and chemical mechanism which control the structure of cytoskeleton. Many proteins such as the family of ERM (ezrin, radixin, moesin) which contribute as actors in remodeling of cytoskeleton (Chen et al. 2013) can change in diabetic situation (Nishida et al. 2014).

\section{Conclusion}

In this research, the viscoelastic properties of normal and diabetic lymphocytes have been investigated and significant differences have been identified. It has been understood that the mechanical properties of healthy and diseased lymphocytes are different in terms of their energy storing and dissipating rates. While cellular migration includes continuous membrane bending and deformation, it can be deduced that the diabetic cells have different migration pattern. Finally, while the most important function of the lymphocytes necessitates their facilitated movement, diabetic cells seem to have problems in performing their tasks. 
Acknowledgements The authors would like to thank warmly all the individuals who contributed in the quarantine laboratory of the national genetic bank center.

\section{Compliance with ethical standards}

Conflict of interest This study was not funded by any company or Grant. Each individual author declares that she/he has no conflict of interest. Author Neda Parvanehpour declares that he has no conflict of interest. Author Shahrokh Shojaei declares that he has no conflict of interest. Author Vahid Faghihi Rezaei declares that she has no conflict of interest. Author Siamak Khorramymehr declares that she has no conflict of interest. Author Vahabodin Goodarzi declares that he has no conflict of interest. Author Fatemeh Hejazi Jahromi declares that she has no conflict of interest.

Ethical approval All procedures performed in studies involving human participants were in accordance with the ethical standards of the institutional and/or national research committee and with the 1964 Helsinki Declaration and its later amendments or comparable ethical standards. The reseach methodology has been checked to be compiled with ethical standards.

Informed consent Informed consent was obtained from all individual participants included in the study.

Open Access This article is distributed under the terms of the Creative Commons Attribution 4.0 International License (http://creativeco mmons.org/licenses/by/4.0/), which permits unrestricted use, distribution, and reproduction in any medium, provided you give appropriate credit to the original author(s) and the source, provide a link to the Creative Commons license, and indicate if changes were made.

\section{References}

Bausch AR, Ziemann F, Boulbitch AA, Jacobson K, Sackmann E (1998) Local measurements of viscoelastic parameters of adherent cell surfaces by magnetic bead microrheometry. Biophys $\mathrm{J}$ 75(4):2038-2049

Cartagena A, Raman A (2014) Local viscoelastic properties of live cells investigated using dynamic and quasi-static atomic force microscopy methods. Biophys J 106(5):1033-1043

Chen EJ, Shaffer MH, Williamson EK, Huang Y, Burkhardt JK (2013) Ezrin and moesin are required for efficient $\mathrm{T}$ cell adhesion and homing to lymphoid organs. PLoS One 8(2):e52368

Dupré L, Houmadi R, Tang C, Rey-Barroso J (2015) T lymphocyte migration: an action movie starring the actin and associated actors. Front Immun 6:586

Gardel ML, Schneider IC, Aratyn-Schaus Y, Waterman CM (2010) Mechanical integration of actin and adhesion dynamics in cell migration. Ann Rev Cell Dev Bio 26:315

González-Cruz RD, Fonseca VC, Darling EM (2012) Cellular mechanical properties reflect the differentiation potential of adipose-derived mesenchymal stem cells. Proc Natl Acad Sci 109(24):1523-1529

Guck J, Schinkinger S, Lincoln B, Wottawah F, Ebert S, Romeyke M, Mitchell D (2005) Optical deformability as an inherent cell marker for testing malignant transformation and metastatic competence. Biophys J 88(5):3689-3698

Hayot CM, Forouzesh E, Goel A, Avramova Z, Turner JA (2012) Viscoelastic properties of cell walls of single living plant cells determined by dynamic nanoindentation. J Exp Bot 63(7):2525-2540

Hecht FM, Rheinlaender J, Schierbaum N, Goldmann WH, Fabry B, Schäffer TE (2015) Imaging viscoelastic properties of live cells by AFM: power-law rheology on the nanoscale. Soft Matter 11(23):4584-4591

Humphrey JD, Dufresne ER, Schwartz MA (2014) Mechanotransduction and extracellular matrix homeostasis. Nat Rev Mol Cell Biol 15(12):802-812

Lekka M, Gil D, Pogoda K, Dulińska-Litewka J, Jach R, Gostek J, Wiltowska-Zuber J (2011) Cancer cell detection in tissue sections using AFM. Arch Biochem Biophys 518(2):151-156

Lekka M, Pogoda K, Gostek J, Klymenko O, Prauzner-Bechcicki S, Wiltowska-Zuber J, Stachura Z (2012) Cancer cell recognitionmechanical phenotype. Micron 43(12):1259-1266

Lim C, Zhou E, Quek S (2006) Mechanical models for living cells—a review. J Biom 39(2):195-216

Mathieu PS, Loboa EG (2012) Cytoskeletal and focal adhesion influences on mesenchymal stem cell shape, mechanical properties, and differentiation down osteogenic, adipogenic, and chondrogenic pathways. Tissue Eng Part B Rev 18(6):436-444

Nishida Y, Aida K, Kihara M, Kobayashi T (2014) Antibody-validated proteins in inflamed islets of fulminant type 1 diabetes profiled by laser-capture microdissection followed by mass spectrometry. PLoS One 9(10): 107664

Otton R, Curi R (2002) Diabetes causes marked changes in lymphocyte metabolism. J Endocrinol 174(1):55-61

Otton R, Soriano F, Verlengia R, Curi R (2004) Diabetes induces apoptosis in lymphocytes. J Endocrinol 182(1):145-156

Peetla C, Vijayaraghavalu S, Labhasetwar V (2013) Biophysics of cell membrane lipids in cancer drug resistance: implications for drug transport and drug delivery with nanoparticles. Adv Drug Deliv Rev 65(13):1686-1698

Plodinec M, Loparic M, Monnier CA, Obermann EC, Zanetti-Dallenbach R, Oertle P, Lim RY (2012) The nanomechanical signature of breast cancer. Nat Nanotechnol 7(11):757-765

Rebelo L, De Sousa J, Mendes Filho J, Radmacher M (2013) Comparison of the viscoelastic properties of cells from different kidney cancer phenotypes measured with atomic force microscopy. Nanotechnology 24(5):055102

Rianna C, Radmacher M (2016) Comparison of viscoelastic properties of cancer and normal thyroid cells on different stiffness substrates. Eur Biophys J 46(4):309-324

Ridley AJ, Schwartz MA, Burridge K, Firtel RA, Ginsberg MH, Borisy G, Horwitz AR (2003) Cell migration: integrating signals from front to back. Science 302(5651):1704-1709

Suresh S, Spatz J, Mills J, Micoulet A, Dao M, Lim C, Seufferlein T (2015) Reprint of: connections between single-cell biomechanics and human disease states: gastrointestinal cancer and malaria. Acta Biomater 23:S3-S15

Trappmann B, Chen CS (2013) How cells sense extracellular matrix stiffness: a material's perspective. Curr Opin Biotechnol 24(5):948-953

Zhao R, Wyss K, Simmons CA (2009) Comparison of analytical and inverse finite element approaches to estimate cell viscoelastic properties by micropipette aspiration. J Biomech 42(16):2768-2773

Publisher's Note Springer Nature remains neutral with regard to jurisdictional claims in published maps and institutional affiliations. 